Research, Society and Development, v. 9, n. 8, e551985642, 2020

(CC BY 4.0) | ISSN 2525-3409 | DOI: http://dx.doi.org/10.33448/rsd-v9i8.5642

\title{
A Aprendizagem Baseada em Problemas (ABP) articulada à formação inicial e continuada de professores de Química
}

Problem-Based Learning (PBL) linked to initial and continuing education for chemistry teachers

\section{Aprendizaje basado en problemas (PBL) vinculado a la educación inicial y continua de los profesores de Química}

Recebido: 15/06/2020 | Revisado: 01/07/2020 | Aceito: 03/07/2020 | Publicado: 16/07/2020

Fernando Vasconcelos de Oliveira

ORCID: https://orcid.org/0000-0001-6367-8562

Vida e Saúde / Universidade Federal de Santa Maria, Brasil

E-mail: nandoufsm@gmail.com

Vanessa Candito

ORCID: http://orcid.org/0000-0003-4663-9590

Vida e Saúde / Universidade Federal do Rio Grande do Sul, Brasil

E-mail: vanecandito@gmail.com

Leonan Guerra

ORCID: https://orcid.org/0000-0003-3111-5401

Vida e Saúde / Universidade Federal do Rio Grande do Sul, Brasil

E-mail: leonan.guerra@yahoo.com.br

Maria Rosa Chitolina

ORCID: https://orcid.org/0000-0002-5240-8935

Universidade Federal de Santa Maria, Brasil

E-mail: mariachitolina@gmail.com

\section{Resumo}

A Aprendizagem Baseada em Problemas (ABP) é uma metodologia que busca trabalhar conceitos e os conhecimentos de forma não linear e contextualizados. Envolve os estudantes em um processo ativo de reflexão e de construção de seu próprio conhecimento, contribuindo para tomadas de decisões, sozinhos ou em grupos, e resolução de problemas. Acredita-se que a $\mathrm{ABP}$ atua como uma estratégia voltada ao estudante, colocando-o como protagonista de sua aprendizagem, e o professor como mediador permitirá o desenvolvimento dos conteúdos, capacitando-o para o desenvolvimento da sua autonomia intelectual e do pensamento crítico. 
Diante dessas perspectivas, o objetivo desse estudo, foi investigar as concepções dos participantes de um minicurso sobre a metodologia ABP, verificando sua aplicabilidade em práticas pedagógicas vinculadas ao ensino de química. Os sujeitos deste estudo foram oito participantes, licenciandos e professores, pertencentes a área de Ciências da Natureza e suas Tecnologias e da área das Ciências Exatas, os quais participaram de um minicurso intitulado “O Ensino de Química por Meio da Aprendizagem Baseada em Problemas (ABP) em um Contexto Temático". O minicurso proporcionou aos participantes um espaço para o diálogo e estabelecimento de novos conhecimentos sobre a ABP. Assim, os sujeitos envolvidos relataram que a metodologia pode auxiliar na prática pedagógica e colaborar com o EnsinoAprendizagem, moldando os saberes, os conhecimentos e as experiências, as quais servirão de suporte quando da utilização da metodologia na práxis.

Palavras-chave: Aprendizagem baseada em problemas; Formação de professores; Metodologias ativas; Práticas pedagógicas.

\begin{abstract}
Problem-Based Learning (PBL) is a methodology that seeks to work on concepts and knowledge in a non-linear and contextualized way. It involves students in an active process of reflection and construction of their own knowledge, contributing to decision making, alone or in groups, and problem solving. It is believed that PBL acts as a strategy aimed at the student, placing him as the protagonist of his learning, and the teacher as a mediator will allow the development of the contents, and enabling him to develop his intellectual autonomy and critical thinking, and in view of these perspectives, the objective of this study was to investigate the participants' conceptions of a short course on the ABP methodology, verifying its applicability in pedagogical practices linked to the teaching of chemistry. The subjects of this study were eight participants, belonging to the area of Natural Sciences and its Technologies and the area of Exact Sciences, in which they participated in a mini-course entitled "Teaching Chemistry through Problem-Based Learning (PBL) in a Context Thematic". The mini-course provided participants with a space for dialogue and the establishment of new knowledge about PBL. Thus, the subjects involved reported that the methodology can assist in pedagogical practice, and collaborate with Teaching-Learning, shaping the knowledge, knowledge and experiences, which will serve as support when using the methodology in praxis.
\end{abstract}

Keywords: Problem-based learning; Teacher training; Active methodologies; Pedagogical practices. 


\section{Resumen}

El aprendizaje basado en problemas (PBL) es una metodología que busca trabajar los conceptos y el conocimiento de una manera no lineal y contextualizada. Involucra a los estudiantes en un proceso activo de reflexión y construcción de sus propios conocimientos, contribuyendo a la toma de decisiones, solos o en grupos, y a la resolución de problemas. Se cree que PBL actúa como una estrategia dirigida al estudiante, ubicándolo como el protagonista de su aprendizaje, y el maestro como mediador permitirá el desarrollo de los contenidos y le permitirá desarrollar su autonomía intelectual y pensamiento crítico. y en vista de estas perspectivas, el objetivo de este estudio fue investigar las concepciones de los participantes de un curso corto sobre la metodología ABP, verificando su aplicabilidad en las prácticas pedagógicas vinculadas a la enseñanza de la química. Los sujetos de este estudio fueron ocho participantes, pertenecientes al área de Ciencias Naturales y sus Tecnologías y al área de Ciencias Exactas, en el que participaron en un mini curso titulado "Enseñanza de la Química a través del Aprendizaje Basado en Problemas (PBL) en un contexto". Temática ". El mini curso proporcionó a los participantes un espacio para el diálogo y el establecimiento de nuevos conocimientos sobre PBL. Por lo tanto, los sujetos involucrados informaron que la metodología puede ayudar en la práctica pedagógica y colaborar con la enseñanzaaprendizaje, dando forma al conocimiento, el conocimiento y las experiencias, que servirán de apoyo cuando se utilice la metodología en la práctica.

Palabras clave: Aprendizaje basado en problemas; Formación de docentes Metodologías activas; Prácticas pedagógicas.

\section{Introdução}

Um dos maiores desafios no Ensino de Ciências é propor estratégias que acompanhem o desenvolvimento dos estudantes (científico, tecnológico, social, cultural, econômico e ambiental). Essas estratégias precisam desvincular-se de propostas engessadas e incorporar mudanças que sejam alternativas ao modelo tradicional de ensino. Assim, faz- se necessário um processo de reforma na educação, que traga mudanças, entre as quais romper com estruturas rígidas e com o modelo de Ensino Tradicional (Libâneo, 1992; Freire, 1996, 2011; Cambi, 1999; Mizukami, 1986; Saviani, 1991). Para isso, é necessário investir na formação inicial e/ ou continuada de professores, que lhes permita recuperar a dimensão essencial do ensino e da aprendizagem (Morin, 2000). Assim, na contramão do ensino tradicional, as experiências desenvolvidas devem inovar, buscar as realidades dos estudantes, visando novas 
possibilidades ao ensino, para mobilizar processos que envolvam não somente a disciplina do professor, mas que permitam um diálogo entre vários componentes curriculares, tornando a aprendizagem ativa.

Nesse contexto, em que se desejam novas metodologias na construção de habilidades, a Aprendizagem Baseada em Problemas (ABP) mostra-se como um método de aprendizagem transdisciplinar. Mesmo sendo um método de aprendizagem eficiente, a ABP ainda enfrenta entraves frente a sua aplicação prática, pois demanda além de tempo para planejamento, uma formação do docente para sua aplicação em aula.

Diante dessas perspectivas, o objetivo desse estudo, foi investigar as concepções dos participantes de um minicurso sobre a metodologia ABP, verificando sua aplicabilidade em práticas pedagógicas vinculadas ao Ensino de Química.

\section{Concepções teóricas da Aprendizagem Baseada em Problemas (APB)}

A APB caracteriza-se por ser uma metodologia que faz uso de problemas cotidianos, reais ou fictícios, e estabelece como finalidade o desenvolvimento do pensamento crítico e as habilidades nas soluções de problemas, promovendo a aprendizagem de conceitos relacionados às áreas de conhecimento estudadas (Ribeiro, 2005).

Na definição por Delisle (2000, p. 5), a ABP é "uma técnica de ensino que educa apresentando aos escolares uma situação que leva a um problema que tem de ser resolvido". Lambros (2004), em uma definição muito semelhante à de Barrows (1986), afirma que a ABP é um método de ensino que se baseia na utilização de problemas como ponto inicial, para adquirir novos conhecimentos que são construídos a partir de um exercício transdisciplinar de pesquisa. Já Barell (2007) interpreta a ABP como a curiosidade que leva à ação de fazer perguntas diante das dúvidas e incertezas sobre os fenômenos complexos do mundo, dos saberes e da vida cotidiana. Ele esclarece que, nesse processo, os alunos são desafiados a comprometer-se na busca pelo conhecimento, por meio de questionamentos e investigação, para dar respostas aos problemas identificados. Leite e Esteves (2006) definem a ABP como um caminho que conduz o estudante para a aprendizagem, assim busca-se resolver problemas a partir da sua área de conhecimento e de outras áreas construindo uma teia de relações de saberes transdisciplinares, com o foco na aprendizagem construtivista, tendo como objetivo desempenhar um papel ativo no processo de investigação e construção do conhecimento investigado. Cabe ao professor vincular o conteúdo curricular com o contexto do tema estudado e estabelecer uma relação entre os saberes com propósito do que se quer ensinar. 
Assim, a ABP estrutura-se na interação de conhecimentos dos indivíduos, a integração de ideias, das interligações dos saberes e o estímulo pela curiosidade sobre os temas, que são fundamentais para o desenvolvimento da aprendizagem dos estudantes, “[...] os modelos curriculares da ABP são largamente construtivistas na sua natureza, pois é dada a oportunidade aos alunos de construírem o conhecimento" (Carvalho, 2009, p. 35).

Os referenciais teóricos sobre $\mathrm{ABP}$, já mencionados, permitem ter definições importantes para a compreensão do seu significado, dando um melhor desenvolvimento no processo de sua aplicação. Assim, esse método foi baseado em estudos de caso inicialmente desenvolvidos na Universidade de Harvard, no século XIX. A primeira instituição de ensino a implantar a ABP foi a Universidade de McMaster, localizada na cidade de Hamilton no Canadá. Essa metodologia de ensino foi aplicada na Faculdade de Ciências Médicas, no final da década de 1960, com o intuito de superar a defasagem entre os anos iniciais do curso, caracterizados por uma formação dominantemente teórica, e o início da prática médica de seus acadêmicos (Lopes et al., 2011). No Brasil, as primeiras Instituições de Ensino Superior a implantar o método ABP em seus currículos foram a Faculdade de Medicina de Marília, em 1997 (Komatsu \& Lima, 2003) e o curso de Medicina da Universidade Estadual de Londrina (UEL), em 1998. Posteriormente, em 2005, a Escola de Artes, Ciências e Humanidades $(\mathrm{EACH})$, conhecida como USP Leste, com o objetivo de desenvolver em seus estudantes uma forte formação acadêmica, científica e profissional, implantou em seu currículo a metodologia da ABP (Araújo \& Sastre, 2009). Na Bahia, seis instituições adotaram de forma parcial ou integral, nos cursos de medicina, a ABP. Entre elas a Universidade Estadual do Sudoeste da Bahia (UESB), a Universidade Federal da Bahia (UFBA), a Escola Bahiana de Medicina e Saúde Pública (EBMSP), a Universidade Estadual de Santa Cruz (UESC), a Universidade Estadual de Feira de Santana (UEFS) e a Faculdade de Tecnologia e Ciências (FTC). A UESC foi a precursora bahiana na implantação desse tipo de atividade no Ensino Aprendizagem, contando inicialmente com o suporte e supervisão da UEL (Tenório \& Silva, 2010).

\subsection{A ABP como alternativa ao modelo tradicional de Ensino}

O Ensino Tradicional ainda é muito enraizado nas instituições de ensino no Brasil e fora do Brasil, pois muitos professores ainda acreditam que o ensino deve ser centrado nos conteúdos. O que requer uma mudança de paradigma, com consciência crítica e comportamentos racionais e justificados (Aikenhead, 2009). Observa-se, também, que este modelo tem sido insuficiente por promover uma visão fragmentada e reducionista nas mais 
diversas áreas do conhecimento científico, tecnológico, social e cultural. Para Chassot (2016), na maioria das vezes, em sala de aula, os professores abordam conteúdos reproduzindo conceitos científicos a partir dos ditames do livro didático. Eles não ampliam as discussões, relacionando-as a temas sociais e assim replicam, desse modo, uma visão reducionista da disciplina.

Estudos na área do Ensino de Química vêm apontando que o ensino atual tem sido ineficaz. Educadores brasileiros dessa área evidenciam a urgência de um novo paradigma educacional, com um ensino voltado à formação de um cidadão mais crítico e atuante na sociedade (Santos \& Schnetzler, 2010).

Os modelos que fundamentam a ABP possuem características das teorias de Ausubel, Bruner, Dewey, Piaget, Rogers e Freire (Ribeiro \& Escrivão Filho, 2011). Ao contrário do que acontece no "Ensino Tradicional", onde inicialmente os conceitos são introduzidos, seguidos de um problema de aplicação, na $\mathrm{ABP}$ os estudantes primeiramente são confrontados com um problema aberto, o qual constitui o ponto de partida para a aprendizagem.

Os problemas, ainda que simulados, se relacionam com o dia a dia e facilitam a integração de aprendizagens de diferentes disciplinas, na medida em que os conhecimentos abordados não são selecionados a priori, mas são identificados durante a resolução do problema como necessários para resolvê-los, independentemente da disciplina a qual pertencem. Sendo assim, caracteriza-se essencialmente por um método que se utiliza de problemas para estimular o desenvolvimento de pensamento crítico e habilidades de solução de problemas, promovendo a aprendizagem de conceitos relacionados às áreas de conhecimento estudadas (Ribeiro, 2010). Para isso, a ABP “[...] utiliza cenários ou situações complexas para instigar estudantes a pesquisar soluções para problemas" e auxilia os alunos a se tornarem ativos e responsáveis pela sua própria aprendizagem (Andrade \& Campos, 2005).

Enquanto na metodologia da ABP o problema é o ponto inicial do aprendizado e deve estar relacionado a um contexto que pode ser real ou hipotético-real, ou seja, que simule uma situação real, na pedagogia tradicional, as aulas normalmente são expositivas e o professor reproduz e transmite os conteúdos, apoiado principalmente no livro didático, e aos estudantes cabe a tarefa de ouvir, anotar, ler, decorar e repetir (Oliveira, 2014).

Notadamente, a prática pedagógica a partir da metodologia $\mathrm{ABP}$, requer do professor uma concepção de Ensino-Aprendizagem que vai além da simples transmissão de conhecimentos disciplinares. Para isso, é imprescindível que o professor saiba trabalhar de forma interdisciplinar, abordando o conhecimento de maneira contextualizada, utilizando-se 
de atividades que permitam a mobilização e elaboração de conhecimentos por meio de discussões e reflexões em grupo. Estes fundamentos e saberes são importantes para a prática docente e principalmente para o trabalho com a metodologia ABP. Segundo Barrowss (2001 apud Ribeiro \& Mizukami 2004), o papel dos docentes aproxima-se ao do facilitador/mediador. Assim, nesta metodologia, os docentes criam situações baseadas em problemas cotidianos, delegam responsabilidades aos alunos e selecionam conceitos que facilitarão a troca de conhecimentos pelos estudantes.

Algumas pesquisas que abordam o ensino de ciências, têm demonstrado que a dificuldade de aprender conceitos científicos em sala de aula está muito relacionada à maneira pela qual o professor trata a disciplina (Mortimer, 2004; Schnetzler, 2004). Apontada por diferentes autores (Pozo, 1998, Ariza, García, \& Del Pozo, 2000, Oñorbe, 2003 apud Andrade \& Campos, 2007) como estratégia para auxiliar a aprendizagem de conteúdos científicos, a escolha dessa metodologia se dá devido à sua importância e eficiência no processo de aprendizagem dos alunos (Santos, 2005).

Nesta concepção, segundo Marks e Eilks (2009), um Ensino de Química eficiente perpassa pela exigência de assumir compromissos com a cidadania, a ética e as mudanças necessárias nas práticas pedagógicas dos professores, a fim de proporcionar a realização de aulas cujos conteúdos são abordados de forma clara e simples, capazes de encorajar os alunos ao interesse dos assuntos de Química. Os autores ainda citam que cabe ao professor avaliar qual a melhor metodologia a ser seguida, devendo estar centrada nos escolares, nas suas necessidades e nos interesses.

Desse modo, a metodologia ABP se apresenta como uma proposição metodológica para o Ensino de Química e de ciências de uma forma geral, que procura tratar os conhecimentos de forma inter-relacionada e contextualizada que envolve os alunos em um processo ativo de construção de seu próprio conhecimento e de reflexão que possa contribuir para tomadas de decisões e resolução de problemas.

Nesse contexto, busca-se fomentar formações iniciais e/ou continuadas, a fim de estimular os docentes a utilizarem metodologias inovadoras, como um processo que possibilite mudanças na prática pedagógica destes, e que permita o desenvolvimento de competências e habilidades no processo formativo dos estudantes, como um método que seja centrado na aprendizagem. Para que o professor tenha uma práxis docente eficaz, a formação docente representa um dos processos fundamentais. Libâneo (2011) ressalta que a formação de docentes é uma prática educativa que visa mudanças no desenvolvimento e na aprendizagem de sujeitos que desejam se preparar profissionalmente para ensinar. Nesse 
sentido, Imbernón (2011) afirma que a formação deve fornecer bases para que o professor desenvolva seu conhecimento pedagógico, cercando-se de elementos que são indispensáveis para a construção do exercício da docência.

Segundo Nóvoa (2009), a formação do professor para o Século XXI deve assegurar a aprendizagem docente e o desenvolvimento profissional dos professores, assim uma articulação da formação inicial com a aprendizagem ao longo da vida, baseada na investigação e no trabalho colaborativo é necessária.

\section{Metodologia}

Este estudo realizou-se durante o $39^{\circ}$ Encontro de Debates sobre o Ensino de Química (EDEQ), realizado pela Universidade do Vale do Taquari (UNIVATES), campus de Lajeado/RS, no ano de 2019, por meio da oferta de um minicurso intitulado "O Ensino de Química por Meio da Aprendizagem Baseada em Problemas (ABP) em um Contexto Temático".

Os sujeitos deste estudo foram oito participantes, pertencentes à área de Ciências da Natureza e suas Tecnologias e da área das Ciências Exatas, inscritos para participar do minicurso ofertado. A identidade dos participantes foi preservada e a identificação dos mesmos realizada por meio de caracteres tipo letra-número: $P 1, P 2, P 3,[\ldots], P 8$.

O minicurso foi desenvolvido a partir do conhecimento do público participante, por meio do seu perfil, sua formação e atuação profissional. Em seguida verificou-se as concepções iniciais dos participantes sobre a ABP, e desenvolveu-se uma discussão acerca dos principais fundamentos teóricos da $\mathrm{ABP}$, suas características, aplicações e dificuldades, e novas perspectivas assimiladas durante o minicurso.

Este estudo seguiu uma metodologia qualitativa. De acordo com Minayo (2001), a pesquisa qualitativa trabalha com o universo de significados, motivos, aspirações, crenças, valores e atitudes, o que corresponde a um espaço mais profundo das relações, dos processos e dos fenômenos que não podem ser reduzidos à operacionalização de variáveis. Os dados foram recolhidos por meio de um questionário semiestruturado, elaborado segundo os aportes de Lambros (2004), cuja aplicação tem como foco a educação básica. Além dos questionários, a coleta de dados se fez também por meio da observação, registros e depoimentos durante o minicurso.

Para a análise das respostas, optou-se pelos procedimentos metodológicos da Análise de Conteúdo de Bardin (2011), compreendendo as etapas de pré-análise; exploração do 
material; definição das categorias; inferências e interpretações, de modo a organizar grupos de respostas de acordo com as semelhanças apresentadas.

\section{Resultados e Discussões}

A importância de conhecer os sujeitos e compreender suas concepções sobre a Aprendizagem Baseada em Problemas (ABP) se dá pelo intuito de propor essa metodologia de ensino não tradicional aos estudantes da educação básica, acadêmicos em formação inicial e aos docentes, na forma de formação continuada, a fim de que o processo de EnsinoAprendizagem seja satisfatório e contemple tanto estudantes quanto professores na sua compreensão. Neste sentido, o Quadro 1, apresenta-se inicialmente as características do perfil dos participantes do minicurso.

Quadro 1 - Perfil dos participantes do minicurso.

\begin{tabular}{|c|c|c|}
\hline Participantes & Formação acadêmica & Atuação profissional \\
\hline P1 & Graduando em licenciatura em Química & - \\
\hline P2 & Graduando em licenciatura em Química & - \\
\hline P3 & Graduando em Ciências Exatas & \\
\hline P4 & Licenciada em Química & Docente em escola pública \\
\hline P5 & Licenciada em Química & Docente em escola pública \\
\hline P6 & Bacharel em Química & Técnica de laboratório \\
\hline P7 & Bacharel/Licenciada em Química & Docente em Ensino Superior \\
\hline P8 & Licenciada em Química & Técnica em assuntos \\
& & educacionais de IES \\
\hline
\end{tabular}

Fonte: elaboração própria dos autores.

Os dados deste estudo, evidenciaram que $50 \%$ dos participantes já tiveram contato com a ABP em sua formação inicial. Assim, destacou-se uma característica interessante do grupo pesquisado. Entre os que responderam que tiveram contato com essa metodologia, 
ainda na formação inicial, $75 \%$ representam um público de graduandos, enquanto que $25 \%$ já apresentavam formação acadêmica.

Porém, ao considerar a relação da ABP com a formação docente, percebeu-se que P2, apesar de apresentar conhecimentos prévios sobre a ABP, não relacionou o tipo de problema adotado e não expressou nenhuma fundamentação à metodologia conforme sua resposta ao questionário:

"Utilizei recentemente em aulas de estágio obrigatório da faculdade. Apresentei um problema aos alunos e eles deveriam resolver de forma prática e rápida.".

Segundo P8, apontou apenas que durante sua formação inicial, obteve noções teóricas de ABP:

"Sim. Nas disciplinas de transposição de conteúdos para o Ensino Médio"

. Aqui é possível observar que mesmo em tempos atuais onde as novas metodologias voltadas à educação em ciências vêm sendo dinamizadas, ainda existem lacunas com relação a abordagem, aprofundamento teórico e prático delas na formação inicial de professores. Isso também ficou claro na fala da P1:

"Apenas ouvi falar, mas nunca cheguei a me aprofundar e nunca foi aprofundado em nenhuma disciplina da graduação."

Neste sentido, por mais que as intuições estejam estabelecendo novas tendências metodológicas, ainda há modos muito tradicionais de ensino, com abordagens superficiais sobre alguns pontos metodológicos que teorizam e exemplificam métodos ativos dentro do processo de Ensino-Aprendizagem. Nesse contexto, percebeu-se a necessidade de formações complementares, a fim de lhes proporcionar subsídios teóricos e práticos, que possibilitem pensar, avaliar, refletir e repensar a sua prática docente de maneira a viabilizar mudanças significativas no processo de Ensino-Aprendizagem. Corroborando com Carvalho (2005, p. 20) que a "[...] mudança só se efetivará à medida que o professor ampliar sua consciência sobre a própria prática, visto que 'pensar a prática' é o ponto de partida para alterá-la. O alargamento da consciência, por sua vez, se dará pela reflexão que o professor realiza de sua ação". 
Research, Society and Development, v. 9, n. 8, e551985642, 2020

(CC BY 4.0) | ISSN 2525-3409 | DOI: http://dx.doi.org/10.33448/rsd-v9i8.5642

Ao serem questionados se a metodologia da ABP associada a uma temática poderia ser usada como estratégia de Ensino-Aprendizagem em suas aulas, todos os participantes concordaram que sim. Essas contribuições ficam evidentes nas respostas dos participantes a seguir:

"Sim. Acredito que metodologias ativas oportunizam ao estudante aplicar conceitos teóricos e mobilizam a aplicabilidade dos conceitos, são muito importantes no processo de Ensino-Aprendizagem” (P5);

"Sim, acredito. É uma forma de sair do papel de detentor do conhecimento, deixando o aluno ser atuante na construção do conhecimento" (P7).

Assim, a abordagem dos conteúdos de Química associados a uma temática, busca o uso de dados, informações e conceitos, para que os alunos possam conhecer a realidade, avaliar situações, soluções, e propor formas de intervenção na sociedade interligados ao seu cotidiano (Marcondes, 2007).

Quando questionados, sobre qual seria o maior problema na implantação de atividades com a ABP nas instituições escolares, obteve-se uma variedade de respostas. Neste sentido, aglutinou-se as repostas e foram criadas duas categorias: 1) os participantes que acreditam que o maior desafio sejam os estudantes, e 2) aqueles que apontam a resistência e despreparo dos professores para trabalhar com uma nova metodologia.

Assim, 37,5\% dos participantes apontaram que as salas de aulas com um número expressivo de estudantes, a falta de recursos por parte deles e a falta de aceitação por parte dos discentes são fatores que criam empecilhos a essa metodologia. Para os outros $62,5 \%$ do grupo, a implementação da ABP esbarra no perfil de profissionais da educação e direções escolares, conforme os enxertos dos participantes a seguir:

"A partir do meu estágio notei que o grande obstáculo é o aceite dos professores, por ainda aceitarem apenas o ensino tradicional. ” (P3);

“O maior problema são "alguns problemas". No meu caso além da falta de alguns recursos tecnológicos para o desenvolvimento de pesquisas, a direção e professores da escola observam sua prática e concluem que você está matando aula, fazem 
Research, Society and Development, v. 9, n. 8, e551985642, 2020

(CC BY 4.0) | ISSN 2525-3409 | DOI: http://dx.doi.org/10.33448/rsd-v9i8.5642

críticas, apontamentos e criam empecilhos ao desenvolvimento dessas atividades diferenciadas." (P7).

Além da resistência dos professores frente a estratégias metodológicas ativas, como a ABP, os participantes apontaram ainda a falta de tempo e de capacitação dos mesmos:

"Uma das dificuldades que acredito haver é a disponibilidade do professor em adotar metodologias e cumprir com os conteúdos previstos. Também há falta de habilidade do professor na elaboração de problemas." (P5);

"Falta de tempo e interesse dos professores, além de capacitação" (P4).

Os participantes concordaram que a $\mathrm{ABP}$ proporciona um processo de EnsinoAprendizagem por meio do desenvolvimento pleno de competências e habilidades. Entretanto, reforçou-se pelos participantes, que conhecer a metodologia não garante a sua utilização plena, sem que antes ocorra uma formação específica como demonstrado pela P8:

"É necessário de muita coisa, eu acho que o professor necessita de muito conhecimento teórico, adquirir conhecimento, saber de um determinado assunto para lançar mão da metodologia. O professor também tem que desenvolver algumas competências e habilidades pra isso (elaboração de textos, por exemplo)".

Ao realizar a análise das respostas dos participantes, percebeu-se que a falta de base de conhecimentos, é sim um fator determinante no sucesso da aplicação de novas práticas pedagógicas que desejam provocar uma mudança na área do ensino. Assim, ao serem questionados sobre a possibilidade da utilização da ABP como metodologia para as práticas pedagógicas, a participante P8 acrescentou:

“Talvez até fosse possivel. Porém eu ainda não tenho experiência para trabalhar com o ABP, eu trabalharia com ela na forma de um curso de extensão no contra turno da escola e quem sabe adquirir experiência estudando e elaborando esses planos de ABP que exigem planejamento. Nós acabamos de ver aqui, que você tem que organizar seu tempo, cada contexto, cada questão cada texto tudo analisado com tempo, então tem 
Research, Society and Development, v. 9, n. 8, e551985642, 2020

(CC BY 4.0) | ISSN 2525-3409 | DOI: http://dx.doi.org/10.33448/rsd-v9i8.5642

que ter prática, porém nós trabalhamos com um número muito grande de aulas no Ensino Médio”.

Esse relato demonstrou que a experiência docente da participante está relacionada à vivência de modelos tradicionais na educação, amparada nas realidades que ainda protagonizam em instituições de Ensino Superior e principalmente da educação básica. É possível compreender que a carga horária excessiva é um dos entraves dos profissionais quando se buscam estudos e construção de planejamentos engajados com propostas metodológicas inovadoras e ativas. Outros dois pontos ainda podem ser enfatizados pela sua fala, o espaço e a experiência.

Ela acredita que o desenvolvimento desse tipo de proposta deva ser no contra turno da aula, ou seja, como um curso extracurricular, muitas vezes ofertado apenas a estudantes interessados, excluindo a metodologia dos demais estudantes que seguirão com métodos engessados de ensino pelo quesito tempo e currículo a ser cumprido. Talvez esse primeiro ponto, justifique o segundo, a falta de experiência sobre a abordagem, por não ter tido um embasamento da ABP em outros cursos e nem mesmo na sua formação inicial.

Percebe-se, na fala da participante P7, que o conhecimento de uma nova metodologia não garante de imediato a sua utilização ou implantação em sala de aula, já que não basta conhecer a metodologia, se não possuir os requisitos básicos para a sua execução:

"A dificuldade está na falta de experiência, é novo pra mim, é a primeira vez que eu vejo como se trabalha, então eu acho que eu encontraria dificuldade na elaboração dessas atividades. Muitas vezes eu poderia preparar uma atividade e prever um tempo e aquilo não daria certo, e eu encontraria uma dificuldade nesse ponto. E eu acho que eu só adquiriria e elaboraria corretamente com a experiência”. (P7, 2020).

Para conhecer e desenvolver a $\mathrm{ABP}$, é necessário que o professor se coloque como professor- pesquisador, busque alternativas dentro do contexto escolar que permitam ao estudante aprender e se sinta motivado a buscar novos conhecimentos, tornando-se questionador. Tornando sua participação ativa, dentro do processo de Ensino-Aprendizagem, como expresso na opinião da P5:

"Pelo o que eu vi da ABP ela consegue atingir as habilidades dos alunos pela criatividade, pelo questionamento, reflexão, argumentação". 
Um estudo realizado por Gomes e Mendes (2016), com a participação de 14 estudantes, que teve como objetivo o aprendizado com relação aos conteúdos de Química Inorgânica, utilizando problemas que envolvessem situações pertinentes ao cotidiano de um professor, abordando assim, tanto os conteúdos específicos da Química Inorgânica quanto algumas metodologias de ensino contidas dentro do próprio problema, como o uso de analogias e metáforas. Os resultados demonstraram que foi possível perceber uma maior motivação dos alunos na busca pela resolução do problema, além dos debates que permearam questões relacionadas ao cotidiano dos professores, apontando para uma possível alternativa dentro do contexto do repensar os processos formativos.

Ao término da atividade, os participantes relataram que para desenvolver uma prática pedagógica que agregue teoria e prática, o docente deve estar em contínuo processo formativo, enriquecendo assim seu planejamento e atuação em sala de aula., conforme demonstra a participante P7:

"Estudar sempre, se preparar para você se reinventar, não basta apenas cobrar isso dos seus alunos".

Imbernón (2011) dá ênfase à formação, porque acredita que ela é o fomento de desenvolvimento pessoal, profissional e institucional dos professores, elevando seu trabalho para transformação de uma prática pedagógica desenvolvida ao longo da profissão, constantemente sujeita à experimentação do novo. Ressaltando assim, que o processo formativo de professores é elemento fundamental para que os docentes aperfeiçoem suas práticas docentes, uma vez que os saberes, conhecimentos e experiências fazem emergir novos pensamentos, comportamentos e ações.

\section{Considerações Finais}

A ABP pode colaborar para o processo de Ensino-Aprendizagem, pois contribui para a melhoria da qualidade de ensino, promovendo aprendizagem mais contextualizada. Porém, para que a metodologia tenha sucesso é necessário que os docentes promovam um ensino transdisciplinar e contextualizado. Para que isso aconteça é imprescindível que o professor vivencie a $\mathrm{ABP}$ em sua prática docente e que esta vivência esteja intimamente relacionada à forma e à maneira com que o professor, durante a sua formação, apropriou-se da concepção do que é ser professor e da forma de como atuar em sala de aula. 
O minicurso possibilitou conhecer a identidade e o perfil acadêmico dos participantes, se tratando de um grupo bem heterogêneo, pois embora fossem de áreas similares, suas experiências em sala de aula eram bastante distintas. Proporcionou um espaço para o diálogo e estabelecimento de novos conhecimentos sobre a ABP. Assim, os sujeitos envolvidos relataram que a metodologia pode auxiliar na prática pedagógica e colaborar com o EnsinoAprendizagem, construindo os saberes, os conhecimentos e as experiências, as quais servirão de suporte quando da utilização da metodologia na práxis.

Evidenciou-se, também, que os participantes valorizaram a metodologia como uma proposta de ensino, porém apontaram alguns sinais de interferência, em relação a questão de planejamento escolar, resistência dos colegas professores e das instituições escolares, além dos estudantes, na qual estão habituados a trabalhar pelo método tradicional. Posto isso, a nova metodologia gera um certo desconforto e um dos indicativos salienta a questão da resistência dos professores, devido à falta de formação inicial e continuada, pois os docentes não se sentem seguros para desenvolver a atividade. Essa falta de segurança pode ser traduzida pela falta de produção na escola, na qual tona-se prejudicada, e os docentes suscetíveis a críticas.

Neste sentido, ressalta-se a importância de formações iniciais tanto continuadas, a partir de metodologias inovadoras, como um processo que possa possibilitar mudanças na prática pedagógica e estimular o desenvolvimento da ABP nas atividades docentes, para fortalecer a construção do conhecimento do professor.

\section{Referências}

Aikenhead, G. S. (2009). Educação Científica para todos. Lisboa: Edições Pedagogo.

Andrade, M. A. B. S., \& Campos, L. M. L. (2005). Análise da Aplicação da Aprendizagem Baseada em Problemas no Ensino de Biologia. In $V$ Encontro Nacional de Pesquisa em Educação em Ciências - SP (p. 01). Bauru, SP, Brasil. Recuperado de http://abrapecnet.org.br/atas_enpec/venpec/conteudo/artigos/1/pdf/p344.pdf

Andrade, M. A. B. S., \& Campos, L. M. L. (2007). A Aprendizagem Baseada em Problemas no Ensino Médio: O Professor Como Tutor. In Atas do VI Encontro Nacional de Pesquisa em Educação em Ciências - SC (p. 01). Florianópolis, SC, Brasil. Recuperado em http://www.nutes.ufrj.br/abrapec/vienpec/autores0.html 
Araújo, U. F., \& Sastre, G. (2009). Aprendizagem baseada em problemas. São Paulo: Summus Editorial.

Ariza, R., García, A. R., \& Del Pozo, R. M. (2000). El conocimiento del profesorado sobre la ciencia, su enseñanza y aprendizaje. In: Palacios, F. J. P., \& Leon, P. C. Didáctica de las Ciencias Experimentales: tema y práctica de la Enseñanza de las Ciencias. Alcoi: Marfil.

Bardin, L. (2011). Análise de conteúdo. São Paulo: Edições 70.

Barell, J. (2007). Problem-Based Learning. An Inquiry Approach. Thousand Oaks: Corwin Press.

Barrows, H. S. (1986). Taxonomy of Problem-Based Learning methods. Medical Education, 20, 481-486.

Cambi, F. (1999). História da pedagogia. São Paulo: Fundação Editora da UNESP (FEU).

Carvalho, A. L. (2005). Os caminhos perversos da educação: a luta pela apropriação do conhecimento no cotidiano da sala de aula. Cuiabá: EDUFMT.

Carvalho, C. J. A. (2009). O Ensino e a Aprendizagem das Ciências Naturais através da Aprendizagem Baseada na Resolução de Problemas: um estudo com alunos de $9^{o}$ ano, centrado no tema Sistema Digestivo. Dissertação (Mestrado em Educação) - Universidade do Minho, Portugal.

Chassot, A. (2016). Alfabetização Científica: questões e desafios para a Educação. Ijuí.

Delisle, R. (2000). Como realizar a Aprendizagem Baseada em Problemas. Porto: ASA.

Freire, P. (1996). Pedagogia da Autonomia. Saberes Necessários à Prática Educativa. São Paulo: Paz e Terra.

Freire, P. (2011). Pedagogia do oprimido. São Paulo: Paz e Terra. 
Gomes, W. G. B., \& Mendes, A. N. F. (2016). A utilização da Aprendizagem Baseada em Problemas para o Ensino de Química Inorgânica num curso de Licenciatura em Química. In XVIII Encontro Nacional de Ensino de Química - SC. Florianópolis, SC, Brasil. Recuperado de http://www.eneq2016.ufsc.br/anais/resumos/R1843-1.pdf

Imbernón, F. (2011). Formação docente e profissional: formar-se para mudança e a incerteza. São Paulo: Cortez.

Komatsu, R. S., \& Lima, V. V. (2003). Manual Famema 2003. Marília: Faculdade de medicina de Marília, 2003.

Lambros, A. (2004). Problem-Based Learning in Middle and High School Classrooms: A Teacher's Guide to Implementation. United States of America: Corwin Press.

Leite, L., \& Esteves, E. (2006). Trabalho em grupo e Aprendizagem Baseada na Resolução de Problemas: Um estudo com futuros professores de Física e Química. In Actas do International Conference PBL 2006 ABP. Lima: Pontifícia Universidad Católica del Perú. Recuperado de http://repositorium.sdum.uminho.pt/handle/1822/9986

Libâneo, J. C. (1992). Democratização da escola pública: a pedagogia crítico-social dos conteúdos. São Paulo: Loyola.

Libaneo, J. C. (2011). Panorama do ensino da didática, das metodologias especifica e das disciplinas conexas nos cursos de pedagogia: repercussão na qualidade da formação profissional. In Longarezi. A., \& Puentes, R. V. (org.). Panorama da didática - ensino e pesquisa. Campinas: Papirus.

Lopes, R. M., Silva Filho, M. V., Marsden, M., \& Alves, N. G. (2011). Aprendizagem Baseada Em problemas: uma experiência no ensino de química toxicológica. Química Nova, (34)7, 1275-1280.

Marcondes, M. E. R. (org). (2007). Oficinas temáticas no ensino público: formação continuada de professores. São Paulo: Imprensa Oficial do Estado de São Paulo. 
Marks, R. \& Eilks, I. (2009). Promoting scientific literacy using a socio-critical and problemoriented approach in chemistry education: concept, examples, experiences. International Journal of Environmental and Science Education, 4, 131-145.

Minayo, M. C. de S. (2001). Pesquisa social: teoria, método e criatividade. Petrópolis: Vozes.

Mizukami, M. G. N. (1986). Ensino: as abordagens do processo. São Paulo: EPU.

Morin, E. (2000). A cabeça bem feita: repensar a reforma, reformar o pensamento. Rio de Janeiro: Bertrand Brasil.

Mortimer, E. F. (2004). Dez Anos de Química Nova na Escola: a consolidação de um projeto da divisão de ensino da SBQ. Química Nova na Escola, 20, 3-10.

Nóvoa, A. (2009). Para uma formación de professores construida dentro de la profesión. Revista de Educación. Ministerio de Educación, 350, 73-202.

Oliveira, F. V. (2014). Aromas: contextualizando o ensino de Química através do olfato e paladar. Dissertação (Mestrado em Educação em Ciências: Química da Vida e Saúde) Universidade Federal de Santa Maria, Santa Maria.

Oñorbe A. (2003) Resolución de problemas. Barcelona: Enseñar Ciencias.

Pozo, J. I. (1998). A solução de problemas: aprender a resolver, resolver para aprender. Porto Alegre: Editora Artmed.

Ribeiro, L. R. C. (2005). A Aprendizagem Baseada em Problemas (PBL): Uma Implementação na Educação em Engenharia na Voz dos Atores. Tese (Doutorado em Educação) - Centro de Educação e Ciências Humanas, Universidade Federal de São Carlos, São Carlos. 
Ribeiro, L. R. C., \& Mizukami, M. G. N. (2004). Uma implementação da aprendizagem baseada em problemas (PBL) na pós-graduação em Engenharia sob a ótica dos alunos. Semina: Ciências Sociais e Humanas, (25)1, 89-102.

Ribeiro, L. R. C. (2010). Aprendizagem Baseada em Problemas PBL. Uma experiência no ensino superior. São Carlos: UFSCar.

Ribeiro, L. R. C., \& Escrivão Filho, E. (2011). Avaliação no ensino superior: um estudo de caso. Acta Scientiarum. Human and Social Sciences, (33)1, 45-54.

Santos, D. M. (2005). O Desenvolvimento de Competências dos(as) professores(as) de química no trabalho com situações-problema. Recife: Universidade Federal Rural de Pernambuco - UFRPE.

Santos, L. P., \& Schnetzler, R. P. (2010). Educação em Química Compromisso com a Cidadania. 3. ed. [S.1.]: Inijuí.

Saviani, D. (1991). Escola e democracia. 24. ed. São Paulo: Cortez.

Schnetzler, R. P. (2004). A pesquisa no Ensino de Química e a Importância de Química Nova na Escola. Química Nova na Escola, 20, 49-54.

Tenório, R. M., \& Silva, R.S. (2010). Capacitação docente e responsabilidade social: aportes pluridisciplinares. Salvador: EDUFBA.

\section{Porcentagem de contribuição de cada autor no manuscrito}

Fernando Vasconcelos de Oliveira - $60 \%$

$$
\begin{gathered}
\text { Vanessa Candito - 20\% } \\
\text { Leonan Guerra - 15\% } \\
\text { Maria Rosa Chitolina - 5\% }
\end{gathered}
$$

